\title{
Short term results of modular bipolar hemiarthroplasty for the treatment of neglected trochanteric femur fracture in the elderly
}

\author{
Towseef Ahmad Bhat ${ }^{1} *$, Zameer Ali $^{2}$, Manik Sehgal ${ }^{1}$
}

\author{
${ }^{1}$ Department of Orthopaedics, Pt. JLN Government Medical College, Chamba, Himachal Pradesh, India \\ ${ }^{2}$ Department of Orthopaedics, Pt. JLN Government Medical College, Baramulla, Jammu and Kashmir, India
}

Received: 15 October 2019

Revised: 25 October 2019

Accepted: 31 October 2019

\author{
*Correspondence: \\ Dr. Towseef Ahmad Bhat, \\ E-mail: towseefortho@gmail.com
}

Copyright: () the author(s), publisher and licensee Medip Academy. This is an open-access article distributed under the terms of the Creative Commons Attribution Non-Commercial License, which permits unrestricted non-commercial use, distribution, and reproduction in any medium, provided the original work is properly cited.

\begin{abstract}
Background: In rural India because of native practitioner culture people tend to neglect orthopaedic injuries and often present late to the hospitals. Bipolar hemiarthroplasty for neglected intertrochanteric fractures of the femur in the elderly yields good clinical results in terms of early postoperative ambulation. This will have a direct effect on the general condition and postoperative rehabilitation.

Methods: Sixteen patients with proximal extracapsular femoral fractures presented average 10.4 weeks late from the day of injury, were treated with modular bipolar hemiarthroplasty. There were 11 men and 5 women, with mean age of 72.8 years (range: 65-83 years). Primary cemented bipolar hemiarthroplasty was performed using the Hardinge lateral approach in a lateral decubitus position. Harris hip score was used for the clinical evaluation of the patients.

Results: Clinically, the Harris hip score at the last follow-up ranged from 92 to 59, with a mean value of 81.7 . Postoperative radiographs showed a good position in all patients. 1 patient developed complication during cementing and 1 case came with dislocation. No case of infection, acetabular erosion, periprostheic fracture or implant loosening was reported in this study.

Conclusions: Primary cemented bipolar hemiarthroplasty is a good choice in elderly patients with neglected intertrochanteric fractures of the femur.
\end{abstract}

Keywords: Hemiarthroplasty, Fracture, Trochanter, Elderly

\section{INTRODUCTION}

By 2050 the number of hip fractures will be about 6.26 million. ${ }^{1}$ An increase in these fractures is on the rise due to the increased life expectancy of the people and osteoporosis. The mechanism of trauma of hip fractures in elderly is mostly a trivial trauma. ${ }^{2}$ Osteosynthesis with various methods is the standard form of treatment for hip fractures. However unstable fractures in elderly with asoociated osteoporosis often make osteosythesis difficult. $^{3}$ The operative treatment methods have come a long way from fixed nail plate devices to modern intramedullary nailing systems. The implant related complications have reduced considerably with introduction of modern implants.

Introduction sliding hip screw considerably reduced complications related to fixed nail plate devices like high rates of cut-out and fracture displacement. ${ }^{3-7}$ However complications such as head perforations, excessive sliding leading to shortening, plate pull-out, and plate breakage continued to be a problem especially with the unstable type of fractures. ${ }^{8-10}$ Osteoporosis and instability are the most important factors leading to unsatisfactory 
results. ${ }^{11,12}$ Also in these elderly patients with unstable osteoporotic fractures, a period of restricted mobilisation is suggested which may cause complications like atelectasis, bed sores, pneumonia, and deep vein thrombosis. Thus fracture stability, bone strength, and early rehabilitation determined the final results in cases of intertrochantric fractures. Intramedullary interlocking devices have shown reduced tendency for cut-outs in osteoporotic bones and also have better results in cases of unstable intertrochanteric fractures. ${ }^{13,14}$ However, the role of the intramedullary devices in unstable osteoporotic and severely comminuted intertrochanteric fractures is still to be defined. However, an ideal treatment method is still rather controversial because of the poor quality of bone mass, comorbid disorders, and difficulty in rehabilitation of these patients.

Various forms of hip arthroplasties are being increasingly used for such fractures. Hip arthroplasty have also shown to achieve early rehabilitation of the patient and good short to mid term results. ${ }^{15,16}$ However, an ideal treatment method is still rather controversial because of the poor quality of bone mass, comorbid disorders, and difficulty in rehabilitation of these patients. The main aim of treatment is elderly with hip fractures is early mobility as prolonged dependence makes such patients prone to life threatening complications. Hip arthroplasty definitely has advantage of early mobility thus helps in preventing postoperative complications.

In rural India because of culture of native practitioners (Desi bone setters) people often present late to the hospital. In such situations even for simple fractures a surgeon can't follow the standard protocol and has to take out of box decisions. This study was done to evaluate the results of modular bipolar hemiarthroplasty in such patients who being bed ridden for months had disuse limb osteoporosis on top of age related senile osteoporosis. Further in such patients prolonged post-operative immobilisation can't be risked as it can have life threating complications.

\section{METHODS}

Between June 2017 and December 2018, a series of 16 patients who underwent cemented bipolar hemiarthroplasties at the department of Orthopaedics Pt. Jawahar Lal Nehru Government Medical College Chamba, HP, India for neglected intertrochanteric fractures were followed up prospectively for a period of atleast 1 year. These patients were all above 65 years of age and were independently mobile. Exclusion criteria were patients with compound intertrochanteric fractures, polytrauma patients, patients who were $<65$ yrs of age and patients who were unfit for surgery.

Preoperative data included: age, sex, side, fracture type (stable or unstable) and mode of injury and time of delay. Post-operative data included time to full weight bearing, average hospital stay and complications. This study was approved by the institutional ethics committee. All the patients provided written informed consents.

All surgical procedures were performed by the same surgical. The operation was performed by using the Hardinge lateral approach in a lateral decubitus position. The femoral head and neck was removed. Meticulous care was taken to preserve the integrity of the greater trochanter, abductor muscles, and all the vascularized bone fragments. The femoral medullary canal was then reamed to the appropriate stem size and diameter. Trial reductions were performed to determine the exact length that would provide the desired tension and tissue balancing of the abductor muscles and an equal leg length. Careful restoration of neck length, offset and version to maximize stability of the hip joint, was also performed during trial. The definitive femoral stem was cemented into the femoral canal with the use of so-called second-generation techniques (medullary lavage, use of an intramedullary cement plug, hand-mixing of cement, use of a cement gun to deliver the cement in a doughy state in a retrograde fashion and to insert antibioticimpregnated cement in all patients). The lesser trochanter was not removed. Any protrusion of cement between reduced bone fragments was cleaned out. The greater trochanter was reduced and stabilized by using the tension band wiring technique after hip reduction or it was just sutured near the prosthesis whenever required (Figure 1). Patients were ambulated full weight bearing on the first post-operative day. They were followed up at 6 weeks, 3 months, 6 months and 12 months. Clinical evaluation was done according to Harris Hip score (HHS). Anteroposterior radiographs of the hip were analyzed at each follow up to note any evidence of loosening. All the patients were followed up for at least 1 year.

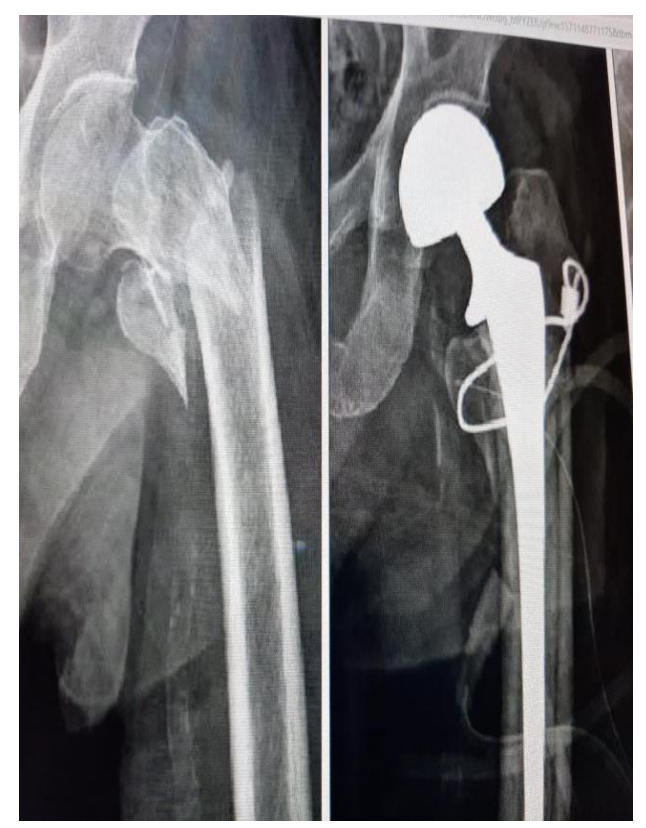

Figure 1: Unstable trochanteric fracture fixed with bipolar hemiarthroplasty. 


\section{RESULTS}

Total 16 cases were included in the study with 11 men and 5 women. All the patients had unilateral injury. 10 patients had right side and 6 had left side injury. The average age of the study group was 72.7 years (range: 65 to 83 years). The average delay from the day of injury to day of surgery was 10.4 weeks (range: 6 to 17 weeks). The mean admission period was 9 days (range: 5-16 days). One patient developed severe hemodynamic abnormalities during cementing who needed prolonged post-operative ICU care. 12 cases were able ambulate independently without support, whereas 4 cases were able to ambulate with assistance. Clinically, the average HHS at the last follow-up was 81.7, ranged from 92 to 59.3 $(18.73 \%)$ cases rated the results as excellent (91-100), 8 $(50 \%)$ as good (81-90), $3(18.7 \%)$ as fair (71-80), and 2 $(12.5 \%)$ as poor $(\leq 70)$ (Table 1$)$.

Table 1: Demographic and clinical data of the patients $(n=16)$.

\begin{tabular}{|ll|}
\hline Variable & Values \\
\hline Men (\%) & $11(68.75)$ \\
\hline Women (\%) & $05(31.25)$ \\
\hline Average age in years & 72.7 \\
\hline Average delay in surgery (in weeks) & 10.4 \\
\hline Average hospital stay in days & 9 \\
\hline Average HHS at final follow up & 81.7 \\
\hline $\begin{array}{l}\text { No. of patients with intraoperative } \\
\text { complications (\%) }\end{array}$ & $01(0.19)$ \\
\hline $\begin{array}{l}\text { No. of cases with postoperative } \\
\text { complications }(\%)\end{array}$ & $01(0.19)$ \\
\hline
\end{tabular}

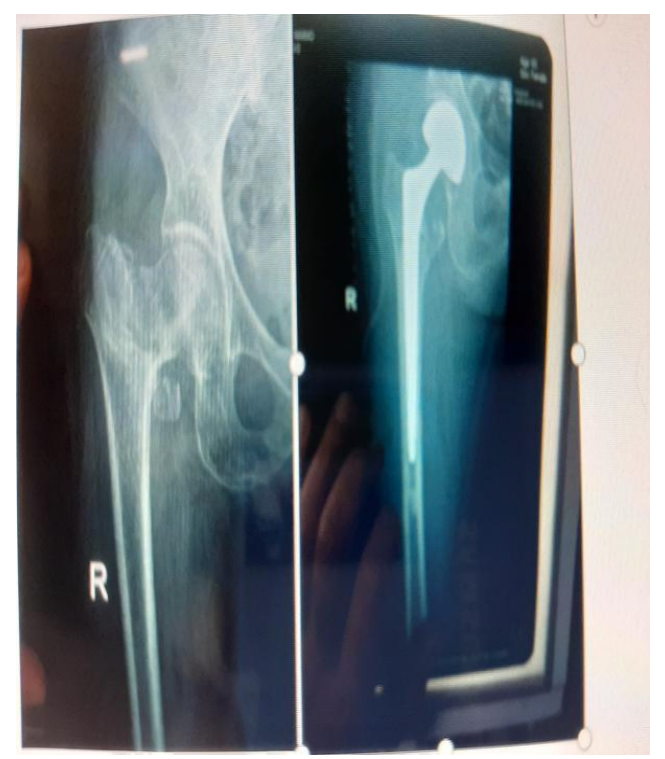

Figure 2: Stable trochanteric fracture fixed with bipolar hemiarthroplasty.

Post-operative radiographs showed a good position in all patients (Figure 2). One case reported with dislocation 12 days after surgery (patient tried to sit on Indian commode) for which open reduction was done. No case of infection, implant loosening, acetabular erosion or significant limb length discrepancy was reported.

\section{DISCUSSION}

Treatment of hip fractures has come a long way from conservative methods to present day advances surgical methods. These surgical methods have drastically reduced the mortality and morbidity rates in elderly with hip fractures. ${ }^{17,18}$ Osteosythesis with various methods is the standard treatment for inter-trochanteric fractures as the consensus is to preserve the normal bone by open reduction and internal fixation. ${ }^{19}$

Arthroplasty is a less frequently used alternative, although it has distinct advantages regarding early mobilisation which is not possible with osteosynthesis in elderly with unstable trochanteric fractures with osteoporosis. $^{20}$ Arthroplasty avoids some complications of internal fixation like malunion, non-union etc. Various studies of internal fixation of both stable and unstable intertrochanteric hip fractures reported a failure rate between 6 and $32 \% .^{21,22}$

Bipolar hemiarthroplasty has distinct advantages over unipolar implants regarding acetabular wear, protrusion, loosening, and dislocation. With time hemiarthroplasty Stems were reconfigured, more in line with total hip replacement designs, to decrease component loosening. Inner bearing motion was introduced to reduce acetabular wear and dislocation rates. Tronzo claimed to be the first to use long, straight-stemmed prosthesis for the primary treatment of intertrochanteric fractures. ${ }^{23}$ since then a number of studies have been published about role of various types of hip arthroplasties in trochanteric fractures in elderly. ${ }^{24-26}$ Modularity allowed for sizing to improve stability. In the management of unstable intertrochanteric fractures, the choice of bipolar hemiarthroplasty prosthesis raised a new question: which stem design should be used? The deficient proximal medial femur is one of the challenges encountered during surgery. It is either to be augmented with calcar replacement prosthesis or the calcar has to be reconstructed. Several investigations have reported good to excellent functional results with the use of calcar replacement femoral prosthesis. ${ }^{27}$

The mean HHS at the final follow up in our study was 81.7 which is comparable to number of published studies. ${ }^{28-30}$ Fen et al in their study have compared the results of bipolar hemiarthroplasty with total hip arthroplasty in proximal femur fractures and found comparable results between the two. ${ }^{31}$

We reported 1 case of infection, I case of intraoperative cement related complication and 1 case of dislocation in our study. No case of acetabular erosion, LLD, periprosthetic fracture or implant loosening was reported in our study. Fewer complications in our study could be 
related to small sample size and short follow up. Besides 4 out of 16 fractures were of stable type. These results are similar to those obtained by Chan et al, who reported revision surgery in only one patient. ${ }^{32}$ However, in a study by Elmorsy et al, both complication rates as well as revision rates were much higher. ${ }^{33}$ They reported the need for revision surgery in four $(9.8 \%)$ patients and complications such as stem loosening and subsidence, infection, dislocation, bleeding peptic ulcer, and intraoperative fracture of the femur.

Our study has a drawback of smaller sample size and short follow up. However our aim was to present short term results only as most of the hip fracture related complications in the elderly are reported in the first year only.

\section{Funding: No funding sources}

Conflict of interest: None declared

Ethical approval: The study was approved by the institutional ethics committee

\section{REFERENCES}

1. Rockwood PR, Horne JG, Cryer C. Hip fractures: A future epidemic? J Orthop Trauma. 1990;4:388-93.

2. Bergström U, Björnstig U, Stenlund H, Jonsson H, Svensson O. Fracture mechanisms and fracture pattern in men and women aged 50 years and older: A study of a 12-year population-based injury register. Osteoporos Int. 2008;19:1267-73.

3. Bannister GC, Gibson AG, Ackroyd CE, Newman JH. The fixation and prognosis of trochanteric fractures. A randomized prospective controlled trial. Clin Orthop Relat Res. 1990;254:242-6.

4. Chinoy MA, Parker MJ. Fixed nail plates versus sliding hip systems for the treatment of trochanteric femoral fractures: A meta-analysis of 14 studies. Injury. 1999;30:157-63.

5. Flores LA, Harrington IJ, Heller M. The stability of intertrochanteric fractures treated w.ith a sliding screw-plate. J Bone Joint Surg Br. 1990;72:37-40.

6. Sernbo I, Fredin H. Changing methods of hip fracture osteosynthesis in Sweden. An epidemiological enquiry covering 46,900 cases. Acta Orthop Scand. 1993;64:173-4.

7. Bess RJ, Jolly SA. Comparison of compression hip screw and gamma nail for treatment of peritrochanteric fractures. J South Orthop Assoc. 1997;6:173-9.

8. Nordin S, Zulkifil O, Faisham WI. Mechanical failure of DHS fixation in intertochanteric fracture femur. Med J Malaysia. 2001;56:12-7.

9. Parker MJ, Handoll HH, Bhonsle S, Gillespie WJ. Condylocephalic nails versus extramedullary implants for extracapsular hip fractures. Cochrane Database Syst Rev. 2000;2:CD000338..

10. Larsson S, Friberg S, Hansson Li. Trochanteric fractures. Mobility, complications, and mortality in 607 cases treated with the sliding-screw technique. Clin Orthop Relat Res. 1990;260:232-41.
11. Kim WY, Han CH, Park JI, Kim JY. Failure of intertrochanteric fracture fixation with a dynamic hip screw in relation to pre-operative fracture stability and osteoporosis. Int Orthop. 2001;25:360-2.

12. Jensen JS, Tøndevold E, Mossing N. Unstable trochanteric fractures treated with the sliding screwplate system. A biomechanical study of unstable trochanteric fractures. III. Acta Orthop Scand. 1978;49:392-7.

13. Hall LG. Comparison of nail-plate fixation Ender's nailing for intertrochanteric fractures. J Bone Joint Surg. 1981;63:24-8.

14. Halder SC. The Gamma nail for peritrochanteric fractures. J Bone Joint Surg Br. 1992;74:340-4.

15. Srivastav S, Mittal V, Agarwal S. Total hip arthroplasty following failed fixation of proximal hip fractures. Indian J Orthop 2008;42:279-86.

16. Green S, Moore T, Proano F. Bipolar prosthetic replacement for the management of unstable intertrochanteric hip fractures in the elderly. Clin Orthop Relat Res. 1987;224;169-77.

17. White BL, Fisher WD, Laurin CA. Rate of mortality for elderly patients after fracture of the hip in the 1980's. J Bone Joint Surg Am. 1987;69:1335-40.

18. Wolfgang GL, Bryant MH, O’Neill JP. Treatment of intertrochanteric fracture of the femur using sliding screw plate fixation. Clin Orthop Relat Res. 1982;163:148-58.

19. Sernbo I, Johnell O, Gentz CF, Nilsson JA. Unstable intertrochanteric fractures of the hip: Treatment with Ender pins compared with a compression hip-screw. J Bone Joint Surg Am. 1988;70:1297-303.

20. Stern MB, Goldstein TB. The use of the Leinbach prosthesis in intertrochantric fractures of the hip. Clin Orthop Relat Res. 1977;128:325-3.

21. Haidukewych GJ, Berry DJ. Salvage of failed internal fixation of intertrochanteric hip fractures. Clin Orthop Relat Res. 2003;(412):184-8.

22. Cho $\mathrm{CH}$, Yoon $\mathrm{SH}$, Kim SY. Better functional outcome of salvage THA than bipolar hemiarthroplasty for failed intertrochanteric femur fracture fixation. Orthopedics. 2010;33:721.

23. Tronzo RG. The use of an endoprosthesis for severely comminuted trochanteric fractures. Orthop Clin North Am. 1974;5:679-81

24. Pho RW, Nather A, Tong GO, Korku CT. Endoprosthetic replacement of unstable, comminuted intertrochanteric fracture of the femur in the elderly, osteoporotic patient. J Trauma. 1981;21:792-7.

25. Harwin SF, Stern RE, Kulick RG. Primary Bateman-Leinbach bipolar prosthetic replacement of the hip in the treatment of unstable intertrochanteric fractures in the elderly. Orthopedics. 1990;13:1131-6.

26. Broos PL, Rommens PM, Deleyn PR, Geens VR, Stappaerts KH. Pertrochanteric fractures in the elderly: Are there indications for primary prosthetic replacement? J Orthop Trauma. 1991;5:446-51. 
27. Grimsrud C, Monzon RJ, Richman J, Ries MD. Cemented hip arthroplasty with a novel cerclage cable technique for unstable intertrochanteric hip fractures. J Arthroplasty. 2005;20:337-43.

28. Elmorsy A, Saied M, Allah AA, Zaied M, Hafez M. Primary bipolar arthroplasty in unstable intertrochanteric fractures in elderly. Open J Orthop. 2012;2:13-1.

29. Kumar GNK, Meena S, Kumar NV, Manjunath S, Raj MKV. Bipolar hemiarthroplasty in unstable intertrochanteric fractures in elderly: a prospective study. J Clin Diagn Res. 2013;7:1669-71.

30. Choy WS, Ahn JH, Ko JH, Kam BS, Lee DH. Cementless bipolar hemiarthroplasty for unstable intertrochanteric fractures in elderly patients. Clin Orthop Surg. 2010;2:221-2.
31. Walia JPS, Sansanwal D, Walia SK, Singh S, Gupta AC. Role of primary bipolar arthroplasty or total hip arthroplasty for the treatment of intertrochanteric fracture femur in elderly. Pb J Orthop. 2011;12:5-9.

32. Chan KC, Gill GS. Cemented hemiarthroplasties for elderly patients with intertrochanteric fractures. Clin Orthop Relat Res. 2000;371:206-15.

33. Elmorsy A, Saied M, Allah AA, Zaied M, Hafez M. Primary bipolar arthroplasty in unstable intertrochanteric fractures in elderly. Open J Orthop. 2012;2:13-7.

Cite this article as: Bhat TA, Ali Z, Sehgal M. Short term results of modular bipolar hemiarthroplasty for the treatment of neglected trochanteric femur fracture in the elderly. Int J Res Orthop 2020;6:53-7. 